Egyptian

Orthodontic Journal

\title{
POSITIONAL CHANGES OF THE MANDIBULAR THIRD MOLAR IN FIRST PREMOLAR EXTRACTION CASES
}

\author{
Hanan A. Ismail* \\ Nadia M. El Harouni*
}

ABSTRACT

This research was designed to study the changes in third molar position after extraction treatment in orthodontics. Pretreatment and post treatment cephalometric and panoramic $x$ ray films belonging to 22 orthodontic patients age ranging between 14 to 20 years treated by first premolar extraction. Results of the study showed significant improvement in the mesioangular inclination of the third molars after treatment. There was also significant forward movement of the third molars after treatment. This study agrees with the expectations of some clinicians concerning improvement in third molar position after extraction treatment.

\section{INTRODUCTION}

The incomplete eruption of third molars remains a serious problem in dentistry primarily because of its high incidence and clinical consequences, which may range from simple caries and pericoronitis to cysts and neoplastic lesions ${ }^{(1)}$.

When planning treatment, orthodontists should take into accounts the presence or absence of third molars, particularly mandibular molar. Consideration should be given to possibility of eruption or impaction when distal movements of first or second molars are required during treatment ${ }^{(2)}$, the effect of extraction of premolar or other permanent teeth in their positioning $a^{(3)}$ the timing of orthodontic treatment ${ }^{(1)}$.

\footnotetext{
* Assistant Professor of Orthodontics, Faculty of Dentistry, Alexandria University.
} 
It has been reported that the more space available on a cephalometric x-ray between the anterior border of the ramus and the second molar the less likely is the impaction of the third molar ${ }^{(2)}$. Rickets drew the same conclusion by directly relating the probability of impacted third molar to the proportion of the third molar extending beyond the anterior border of the ramus. However, in contrast the work of Graber which indicates that there are many factors involved in the eruption of third molars including direction of eruption. This is the reason that we only discuss probability of eruption as a function of space available which can not be predicted with certainty. Dr. Graber feels for this reason that those who expected proper eruption routinely as a consequence of bicuspid extraction will be disappointed ${ }^{(3)}$.

The eruption or impaction of mandibular third molars has been related to genetic factors ${ }^{(4)}$ and even attributed to eating habits of the modern civilized man. Some authors attempted to correlate the extraction of teeth adjacent to the third molar and its eruption ${ }^{(2,5,6)}$.

According to Steiner and Fernandes ${ }^{(7)}$, orthodontic therapy requiring extraction of first premolars could allow mesial movement of the permanent molars, in view of this, some authors ${ }^{(5,6,9,10,11,12)}$ concluded that orthodontic treatment including extraction of premolars would make eruption of mandibular third molars easier and reduce the incidence of impaction in these teeth. This idea have been opposed by other researchers ${ }^{(13)}$ who do not see a correlation between treatment including extraction of premolars and eruption of the third molars. Other authors have presented studies suggesting that in cases where extractions are required the choice should be the second molars instead of the premolars, so as to make eruption of the adjacent third molars easier. The drawback to this extraction decision is the requirement for additional treatment to align the third molar following eruption ${ }^{(14,15,16)}$.

In $1974^{(17)}$ Turley presented probability curves which verified the effect of making additional space available on the possibility of eruption of third molars. It was observed that $7 \mathrm{~mm}$ of additional space, the width of a bicuspid, decreases the chance of impaction by about $70 \%$. Anchorage requirements should be considered, but clinicians may use the rule that $1 \mathrm{~mm}$ additional space improves the chance of eruption by $10 \%$. For example, if we were to remove $4 \mathrm{~mm}$ crowding and move the lower incisor lingually $2 \mathrm{~mm}$ in an extraction case, this would deduct $4 \mathrm{~mm}$ from the $7 \mathrm{~mm}$, leaving only a 30\% improvement in the likelihood of eruption. 
In the present study the mesioangluar inclination and forward movement of third molar was studied in 22 orthodontic cases treaded with 4 premolar extraction.

\section{Material \& Methods}

Lateral Cephalometric and Panoramic radiographs belonging to 22 patients treated by 4 first premolar extractions and moderate anchorage requirements were collected. Pre and post treatment radiographs were available for the 22 patients and treatment time averaged 24 months. Age range between 14-20 y. All cases had both mandibular $3^{\text {rd }}$ molars present before and after treatment showing mesioangular inclination. Two $3^{\text {rd }}$ molars of the 44 studied showed horizontal impaction in a mesial direction.

The long axis of the wisdom tooth was drawn as the line perpendicular to the widest mesiodistal diameter of the molar at the middle (bifurcation site).

On the Panoramic view the angle between the long axis of the wisdom to the mandibular plane (Line tangent to the lower border of the mandible) was measured on both the right $\&$ left sides before and right after treatment (fig. 1).

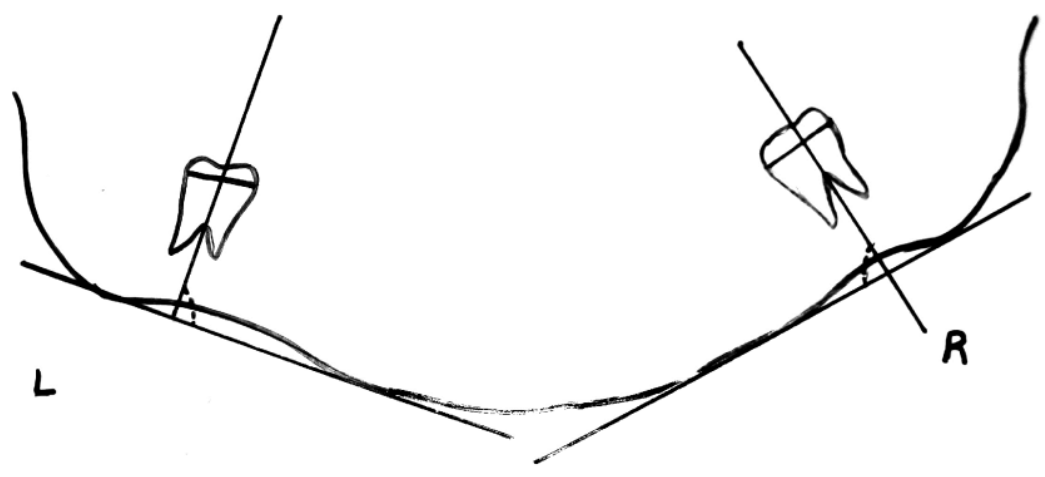

Figure: 1

On the cephalometric x-ray the mesioangular inclination of the $3^{\text {rd }}$ molar was measured the same way.

Forward movement of the third molar was measured from the most anterior point of the wisdom (on the contact area) perpendicular to the RDI reference line ${ }^{(1)}$ in millimeter (Fig. 2). 
Egyptian

Orthodontic Journal

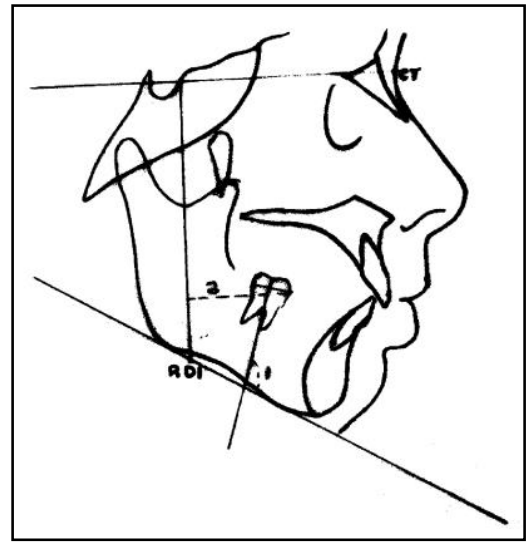

Figure: 2

CT Horizontal reference line passes through point $\mathrm{C}$ (the most anterior point of the cribriform plate at the junction with the nasal bone) and point $\mathrm{T}$ (the most superior point of the anterior wall of sella turcica at the junction with tuberculum sella).

RDI Vertical reference line is a perpendicular line to the CT plane at $\mathrm{T}$.

1- Angle between long axis of the wisdom and mandibular plane.

2- Perpendicular distance between the most anterior contact point of the third molar and RDI line.

\section{Statistical analysis:}

Means values of measurement were calculated before and after treatment. From the Panoramic and Cephalometric x ray films. Comparison of these values was done using paired $t$ test or Wilcoxon signed ranks test for values of RDI because they were not normally distributed. Percent change was calculated using this equation:

[(values after treatment - values before treatment) / values before treatment]* 100. Median values of percent change were calculated. Bar chart was used for graphical presentation.

\section{For reliability:}

Only one examiner was responsible for scoring. To ensure reliability and consistency of scoring, $30 \mathrm{x}$ rays were rescored another time and the values of the two measurements compared, negligible differences were found between the two scoring measurements which ensured examiner reliability. 
Egyptian

Orthodontic Journal

\section{RESULTS}

Table I: Angular and Horizontal changes in Position of Third molars before and after treatment.

\begin{tabular}{||l|c|c|c|l|l||}
\hline \hline & $\begin{array}{c}\text { Before } \\
\text { Mean } \pm \text { SD }\end{array}$ & $\begin{array}{c}\text { After } \\
\text { Mean } \pm \text { SD }\end{array}$ & $\begin{array}{c}\text { Difference } \\
\text { Mean } \pm \text { SD }\end{array}$ & T test & P value \\
\hline Panorama & $65.33 \pm 13.63$ & $75.97 \pm 14.58$ & $-10.64 \pm 8.89$ & 7.18 & $<0.0001^{*}$ \\
\hline Cephalometric & $72.45 \pm 13.93$ & $87.05 \pm 13.06$ & $\begin{array}{l}-14.60 \quad \pm \\
13.31\end{array}$ & 4.91 & $<0.0001^{*}$ \\
\hline $\begin{array}{l}\text { Cephalometric } \\
\text { RDIII }\end{array}$ & $17.57 \pm 8.29$ & $23.09 \pm 7.47$ & $-5.52 \pm 3.05$ & 4.11 & $<0.0001^{*}$ \\
\hline
\end{tabular}

*: Statistically significant

II: Wilcoxon signed ranks test used instead of $\mathrm{t}$ test

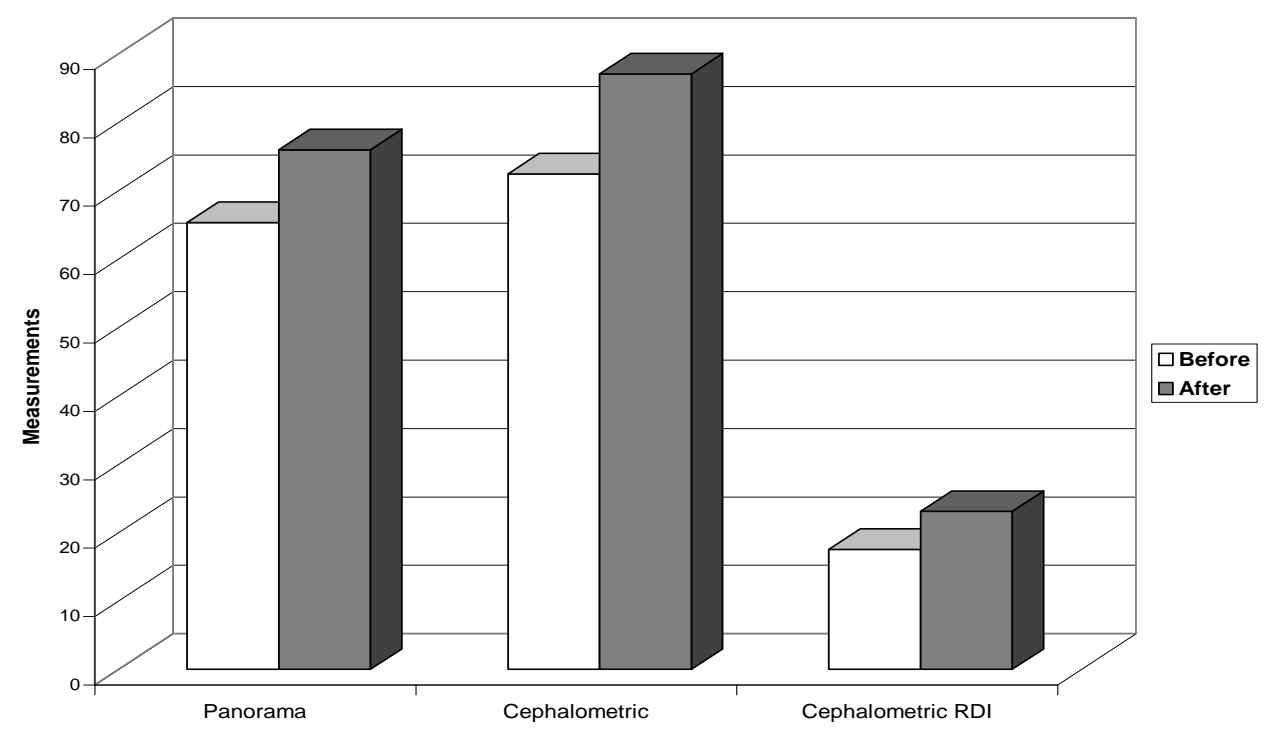

Figure 3: Graph showing changes in molar position after extreaction treatment

There was a significant change in the mesioangular position in the third permanent molar seen in both the panoramic and the cephalometric $\mathrm{x}$ rays. There was also a significant forward movement of the third permanent molar seen in the cephalometric $\mathrm{x}$ ray following premolar extraction. 


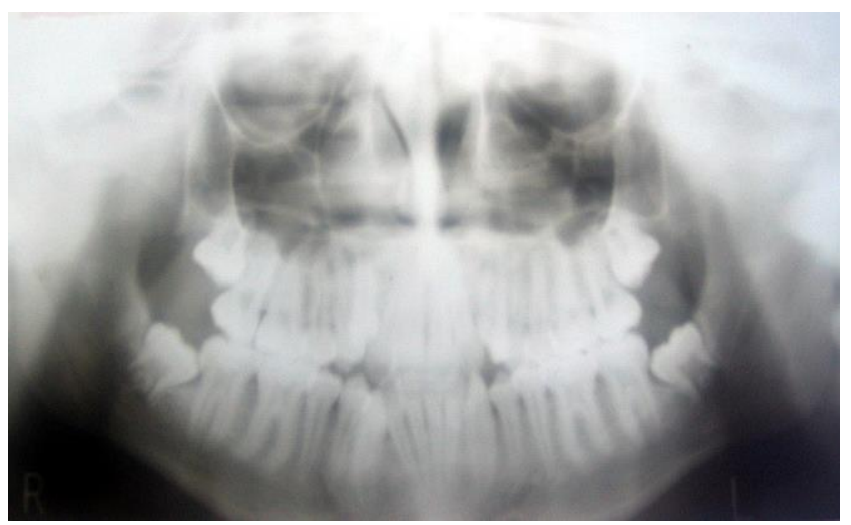

Figure 4: Panoramic $x$ ray showing uprightening of the third molar following first premolar extraction treatment.

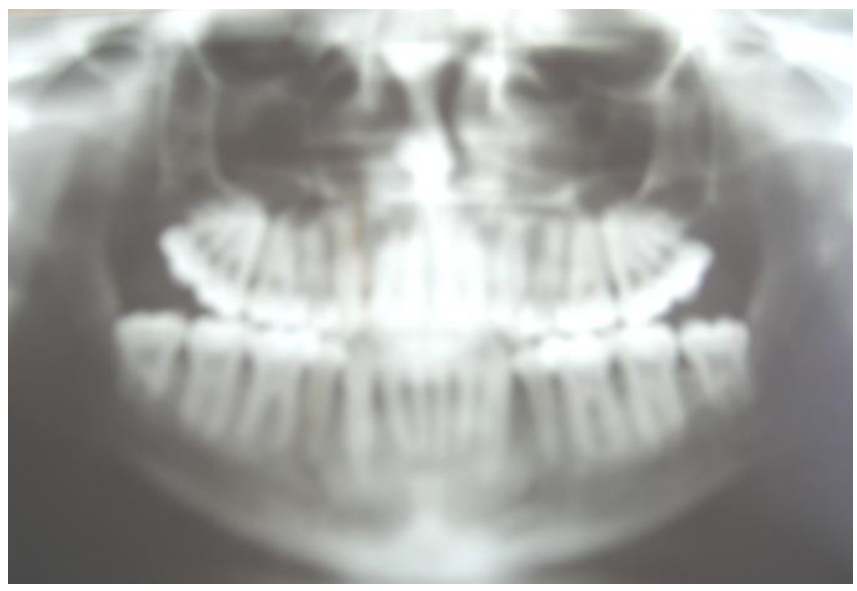

Table 2: Percent change among three measures before and after movement:

\begin{tabular}{||l|c|c|c||}
\hline & Panorama & Ceph & Ceph RDI \\
\hline Min- max & $0-78.13$ & $-1.16-64.29$ & $2.27-130.00$ \\
\hline Median & 13.86 & 13.80 & 31.47 \\
\hline Mean \pm SD & $17.82 \pm 16.73$ & $22.97 \pm 22.41$ & $43.20 \pm 36.73$ \\
\hline
\end{tabular}

Volume 32 - December 2007 
Table 2 shows the percentage change in the third molar angulation and position after extraction treatment. The mean percentage improvement in the mesioangular position of the third molar was $17.82 \%$ in the panoramic $\mathrm{x}$ ray and $22.97 \%$ in the cephalometric $\mathrm{x}$ ray. The mean percentage forward movement of the third molar seen in the cephalometric $\mathrm{x}$ ray following extraction treatment was $43.2 \%$.

\section{DISCUSSION}

The high risk of the third molars presenting problems to anyone in the late teens or early twenties makes it a constant headache to patients and dentists.

It was noticed clinically by the authors that patients who underwent premolar extraction during orthodontic treatment has better chances of the uneventful third molar eruption, so it was thought of interest to try and prove it or refute it through research.

The results proved that third molars were significantly more upright after orthodontic treatment with premolar extraction. Capelli ${ }^{(1)}$ et al published results in accordance with this finding, as in a group treated with premolar extraction where wisdoms weren't impacted, they found that the inclination of the third molar crown was higher before treatment than after, suggesting a forward root movement that rectified the mesial inclination of the crown, as described also by Salzmann.

Significant forward movement of $3^{\text {rd }}$ molars was also observed, this agrees with Steiner ${ }^{(7)}$ and Fernandes ${ }^{(8)}$ who reported that extraction of first premolar would allow mesial movement of wisdoms. ${ }^{(5,6,9,10,11,12)}$

The cases were treated by moderate anchorage meaning that about 3-4 mm of additional space were provided for molar eruption. According to Turley ${ }^{(17)}$ this gives $30.40 \%$ less chance of third molar impaction. This also means that even if the space of the molar is enough the third molar would shift forward for a better position, even for extraction, and this would facilitate its removal and decrease the amount of bone removal necessary in surgical extraction.

Many clinicians including Costich ${ }^{(19)}$ and Hoek $^{(20)}$ adopt the routine prophylactic removal of a "slightly tilted or impacted $3^{\text {rd }}$ molar tooth" in the early teens, as they do not predict any spontaneous improvement in the position. Some went further to recommend enucleation of the third molar bud at 7-10 years for fear of future problems ${ }^{(21-22)}$. 
This paper would strongly oppose such recommendations for any patient who might later need extraction orthodontic treatment which might help in third molar eruption or at least render its removal less traumatic.

\section{REFERENCES}

1. J. Capelli: Mandibular growth and third molar impaction in extraction cases. Angle Orthod. 1991;3: 223-229.

2. Bjork A: Mandibular growth and third molar impactions. Acta Odontologica Scandinavia.1956;14: 231-72.

3. Schulhof RJ: Third molar and orthodontic diagnosis. Journal of Clinical Orthodontics. 1976;April 272-281.

4. Garn SM. et al: Third molar formation and its development course.The Angle Orthod. 1962;32: 270-279.

5. Kaplan RG.: Some factors related to mandibular third molar impaction.The Angle Orthod.1975;45(3): 153-158.

6. Kaplan RG: Mandibular third molars and post retention crowding. Am J Orthod.1974; 66(4): 411-430.

7. Steiner CC: Cephalometric for you and me. Am J Orthod.1953; 39(10): 729-755.

8. Quoted from Schulhof RJ: Third molar and orthodontic diagnosis JCO. 1976, April (272-281). Fernandes AFC: Analysis of lower first molars mesial movement, Class I biprotrusion cases treated with first premolar extraction [Master of Dental Science thesis] Federal University of Rio de Janeiro, Dental School, 1978.

9. Silling GBS: Development and eruption of mandibular third molar and its response to orthodontic therapy. The Angle Ortho.1973;43(3): 271-278.

10. Weinstein S: Third molar implication in orthodontics. J Am Dent ASS.1971;82(4): 819-823.

11. Dierkes DD: An investigation of the mandibular third molars in orthodontic cases.The Angle Orthod.1975;45(3): 207-212.

12. Faubion BH: Effect of extraction of premolars on eruption of mandibular third molars. J Am Dent Assoc.1968;76(2):316-320.

13. McCoy JR: A Study of growth potential. Am J Orthod.1965; 51(2): 79-97. 
Egyptian

Orthodontic Journal

14. Bishara SE, Burkey PS: Second molar extractions: a review. Am J Orthod Dentofacial Orthop.1986; 89(5): 415-424.

15. Huggins DG, McBride LS: The eruption of lower third molars following the loss of lower second molars: a longitudinal cephalometric study. Brit J Orthod.1978;5(1): 13-20.

16. Gooris CEM, Artun J, Joondeph DR: Eruption of mandibular third molars after second molar extractions: A radiographic stidu. Am J of Orthod Dentofacial Orthop.1990; 98: 161-67.

17. Turley PK: A computerized method of forecasting third molar space in mandibular arch. Paper read at NIDR Meeting, 1974 Quoted from Schulhof RJ: Third molar and orthodontic Diagnosis JCO. 1976, April (272-281).

18. Salzmann JA: Practice of orthodontics, Vol 1, fourth edition Philadelpma. JB Lippin vott Co, P181, 1966.

19. Costich ER: Removal of third molar as a phase of preventive dentistry. Dent Abstracts.1968; 13:9.

20. Hoek RB: Third molars. J Am Dental Ass.1964; 68(5): 541-548.

21. Ricketts RM: Third molar enucleation: Diagnosis and treatment. J Calif Dent Assoc.1976; 4: 52-57.

22. Henry CB: Prophylactic odontectomy of the developing mandibular third molar. Am J Ortho.1938; 24: 72-84. 